\title{
NOTE
}

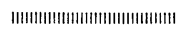

\section{Fitting Function for the Thermal Neutron Distribution in Water due to a ${ }^{252} \mathrm{Cf}$ Source ${ }^{\dagger}$}

\author{
Masatoshi Fujishiro, Tatsuo TABAtA, Junichiro Furuta and Eiichi HiraokA \\ Radiation Center of Osaka Prefecture, Shinke-cho, Sakai-shi, Osaka \\ Tadashi Tsujimoto, Kenichi OKamoto and Kosuke Katsurayama \\ Research Reactor Institute, Kyoto University, \\ Kumatori-cho, Sennan-gun, Osaka
}

Received November 18, 1976

The distribution of the quantity $A(r) r^{2}$, thermal neutron counts multiplied by the square of distance, in water due to a pointsource is interesting from the practical points of view such as calibration of the neutron source by the water bath method, estimation of Fermi age of the source neutrons down to the thermal energy, etc. In this note is described a fitting function for the distribution of $A(r) r^{2}$ in water due to a near-point ${ }^{252} \mathrm{Cf}$ source which is now widely of interest as a useful neutron source.

The experimental data used to investigate the fitting function have been obtained with a small $\mathrm{BF}_{3}$ counter which seems suitable, in comparison with the foil-detector, for measuring a neutron source of $\$ 10^{5}$ outputs per second because of its large efficiency. The $\mathrm{BF}_{3}$ counter used was of the type ND 8522-60 manufactured by Mitsubishi Electric Inc., and its effective volume and efficiency for the thermal neutrons was nominally $1 \mathrm{~cm}^{3}$ and 0.074 counts per second per unit neutron flux, respectively. Figure 1shows the experimental arrangement. The $\mathrm{BF}_{3}$ counter was put into the bottom of an Alpipe $1.2 \mathrm{c} \mathrm{m}$ in diameter by $100 \mathrm{~cm}$ in length,

$\dagger{ }^{252} \mathrm{Cf}$ 線源による水中での熱中性子分布に対する 適合関数. 藤代正敏, 多幡達夫, 古田純一郎, 平 岡英一, 辻本忠*, 岡本賢一*, 桂山幸典*：大阪 府立放射線中央研究所, 堺市新家町

* 京都大学原子炉実験所, 大阪府泉南郡熊取町
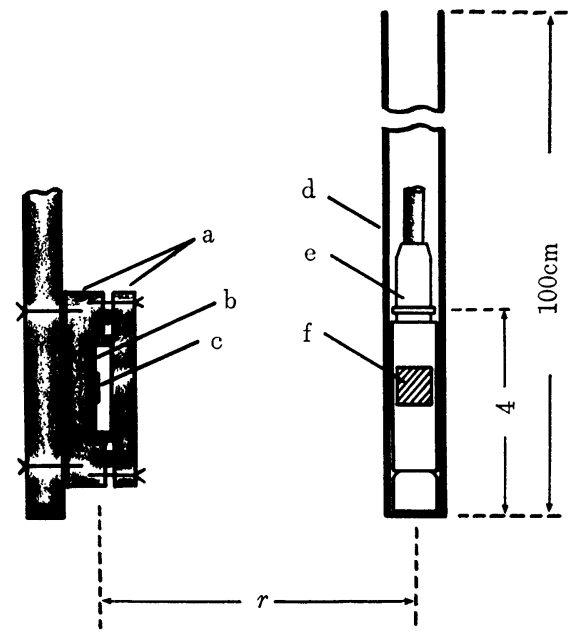

Fig. 1 Experimental arrangement. a: Source holder (made of aclylite), b: Platinum backing ( 1 in. dia. $\times 0.03 \mathrm{~cm}$ ), c: ${ }^{252} \mathrm{Cf}$ source $(\sim 0.8 \mathrm{~cm} \mathrm{dia.}), \quad \mathrm{d}$ : Al-pipe $(1.2 \mathrm{~cm}$ dia. $\times 100 \mathrm{~cm})$, e: $\mathrm{BF}_{3}$ counter, $\mathrm{f}$ : Effective volume $\left(\sim 1 \mathrm{~cm}^{3}\right)$.

and the residual space of the Al-pipe was filled with paraffin to minimize spatial inhomogeneity. The ${ }^{252} \mathrm{Cf}$ source consisted of electrically deposited layer of $0.8 \mathrm{~cm}$ in diameter on a thin platinum backing, and its nominal quantity was $0.1 \mu \mathrm{g}$. The measurement was carried out in a water bath $90 \mathrm{~cm}$ in diameter by $90 \mathrm{~cm}$ height filled with pure water of about $10^{6} \Omega \cdot \mathrm{cm}$ electric resistance. The net counting rate $A(r)$ of thermal neutrons was determined as the difference between the counting rates measured with and without a Cd-cover of $0.5 \mathrm{~mm}$ 
thickness on the $\mathrm{BF}_{3}$ counter. The experimental results are shown with solid circles in Fig. 2; the abscissa denotes the distance $r$ from the neutron source and the ordinate the counting rate $A(r)$ multiplied by $r^{2}$. The measurements were repeated five times at each position, and the rms relative error of the present data was $5.0 \%$.

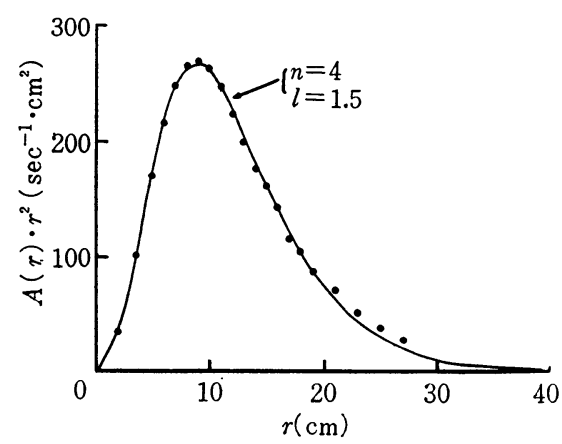

Fig. 2 Comparison of the experimental results with the fitting function (Eq. (2) with $C_{0}=-4.440 \times$ $10^{2}$ ).

In order to reproduce the experimental values of $A(r) r^{2}$, we use a series of orthogonal functions constituted from weighted Laguerre polynomials and write as

$$
A(r) r^{2}=C_{0} e^{-r / 2 l} \sum_{j=1}^{n} C_{j}\left\{L_{j}(r / l)-1\right\},
$$

where $L_{j}(r / l)$ is the Laguerre polynomial of order $j$ and of scale factor $l, C_{j}$ a constant for a given distribution, and $\mathrm{C}_{0}$ a coefficient which depends on the efficiency of the $\mathbf{B F}_{3}$ counter used. Subtraction of unity in the bracket is based on the requirement that the value of $A(r) r^{2}$ should be zero for $r=0$. The constant $C_{1}$ is identically equal to unity, and $C_{j}(j=2, \cdots, n)$ and $l$ are sought by the least-squares fit. Figure 3 shows, with $n$ as a parameter, the relation between $l$ and the rms relative error $\delta$ of fit in which the mean has been taken with weights proportional to the square of the fitted values. It is seen from this figure that $\delta$ falls below $2.5 \%$ for $n \geq 6$ when $l$ takes a value between 1.0 and $3.0 \mathrm{~cm}$. From the comparison with the experimental error, however, it seems enough to adopt $n=4$ and

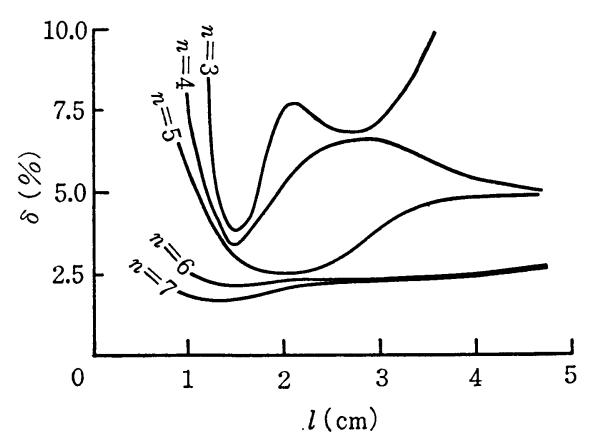

Fig. 3 Relation between the scale factor $l$ and the rms relative error $\delta$ of fit.

the value of $l$ which minimizes $\delta$. The optimum value of $l$ is estimated as $1.5 \mathrm{~cm}$, for which $\delta$ is about $3.3 \%$. The constants $C_{f}$ in this case are given in Table 1 , and the fitted function is shown with solid line in Fig. 2. Thus the fitting function has been determined as

$$
A(r) r^{2}=C_{0} e^{-r / 3.0} \sum_{j=1}^{4} C_{j}\left\{L_{j}(r / 1.5)-1\right\} .
$$

The coefficient $C_{0}$ depends on the thermal neutron detector used, and for a different detector of known efficiency it can be determined uniquely from Eq. (2) by measuring $A(r)$ at a single position. The peak position of the $A(r) r^{2}$ curve is estimated from Eq. (2) as $r_{0}=8.6 \mathrm{~cm}$.

Table 1 Constants $C_{j}(j=2 \sim 4)$ peculiar to the ${ }^{252} \mathrm{Cf}$ neutrons

\begin{tabular}{c|c|c}
\hline$C_{2}$ & $C_{3}$ & $C_{4}$ \\
\hline-0.9840 & 0.3225 & 0.0114 \\
\hline
\end{tabular}

The reduced chi-square $\chi_{\nu}{ }^{2}$ of the present fit is 0.66 which is mainly caused by the discrepancy at large $r$, as is seen in Fig. 2 . When a more intensive, but a small-sized, source is used to diminish the rms relative error and a higher value of $n$ is adopted, the discrepancy would be improved yielding a value of $\chi_{\nu}{ }^{2}$ nearer to unity. As to the integral $\int_{0}^{\infty} A(r) r^{2} d r$, to which the neutron yields from a point-source is proportional ${ }^{11}$, one can analytically integrate Eq. (2) to obtain 


$$
\int_{0}^{\infty} A(r) r^{2} d r=-7.93 \times C_{0}
$$

With Eqs. ( 2 ) and ( 3 ), therefore, the calibration of a ${ }^{252} \mathrm{Cf}$ source by the water bath method can be so simplified that one is required to measure $A(r)$ only at a single position.

Once the fitting function for the $A(r) r^{2}$ distribution is determined as Eq. (2), the fitting function for the $A(r) r^{4}$ distribution is simply given by

$$
A(r) r^{4}=C_{0} r^{2} e^{-r / 3.0} \sum_{j=1}^{4} C_{j}\left\{L_{j}(r / 1.5)-1\right\}, \text { (4) }
$$

which also is useful for estimating Fermi age $\tau$ of the ${ }^{252} \mathrm{Cf}$ neutrons according to the formula

$$
\tau=\frac{\int_{0}^{\infty} A(r) r^{4} d r}{6 \int_{0}^{\infty} A(r) r^{2} d r} .
$$

The present method of estimating neutron yields and Fermi age would particulary be useful for short life sources, when their fitting functions for the $A(r) r^{2}$ distribution have been prepared beforehand.

\section{References}

1) B.T. Feld: in Experimental Nuclear Physics, Vol. II (ed. E. Segrè; John Wiley \& Sons Inc., p. 455 1953) 